\title{
DISCRETE EVENT-BASED RAILWAY SIMULATION MODEL FOR ECO-EFFICIENCY EVALUATION
}

\author{
Amorim, G. A.; Lopes, L. A. S. \& Silva Junior, O. S. \\ Instituto Militar de Engenharia, Seção de Fortificação e Construção, Rio de Janeiro, RJ, Brasil \\ E-Mail: gracianoamorim2014@gmail.com, laslopes@uol.com.br, orivalde@ime.eb.br
}

\begin{abstract}
Based on the discrete event-based simulation method, this paper aims to model the Paranaguá "KM5" Railyard, looking at the inbound and outbound movement of trains and wagons from an ecologic perspective. The originality of this paper comes from the inclusion of the train parameters and ecoefficiency concerning train operation. Moreover, it helps the operator to define a range of optional strategies for wagon classification, which would be more environmentally friendly, also providing a basis for further research on this theme. This research method is quantitative, based on visits to the railyard, interviews with rail operators, the original railyard's geometrical design, real operation charge for 2016, as well as theoretical studies. The main findings are that the analysis of the simulated cases can be applied by the rail manager to the railyard's operation manual. The implication for theory and practice is that the findings can also contribute, with different parameters of decision, not only the reduction of time taken but also with consideration of the environmental impact.

(Received in April 2020, accepted in July 2020. This paper was with the authors 1 month for 2 revisions.)
\end{abstract}

Key Words: Railyard, Discrete Event-Based, Simulation, Eco-Efficiency, Anylogic, Paranaguá

\section{INTRODUCTION}

Simulation is the technique of creating, in a virtual environment, a representation of a real system using mathematical models to study the behaviour under normal operating conditions; or to test hypotheses with the security of performing these tests without risks and with low cost involved. The concept of simulation has been spreading with increasing speed in recent years with the emergence of new, more robust, and versatile software [1].

The simulation methods can be divided into three categories: Monte Carlo, where events are randomly generated and in large volume; Continuous Simulation, which analyses situations where continuous changes occur over time; or Discrete Events, an adopted method in this paper, where changes occur at certain moments [2].

Railyards involve complex asset management, with high operating costs and environmental impact. In this sense, some authors have developed models to evaluate the environmental efficiency of projects in general, such as the World Bank studies [3], as well as their adaptation to freight locomotive analysis [4]. These studies allow the evaluation and comparison of various rail transport solutions by eco-efficiency indicators concerning global references.

Fan et al. [5] propose a simulation method to evaluate systems of abrasive method grinding, aiming for more efficient processes to remove defects from rails, such as corrugation, crack, spalling and squat, prolonging the rail's service life. The authors adopted the system SIMPACK software to verify the performance in terms of dynamics indices (lateral and vertical vibration accelerations, axle transverse force and derailment coefficient). The dynamic simulation model carried out by SIMPACK, allows investigation into the performance of the designed device, showing the variation of dynamic indices in terms of speed and geometry characteristics.

Wang and Chen [6] propose a simulation method of production logistics, analysis of results and identification of bottleneck using the FLEXSIM system. By this model, they proposed optimization of methods, reducing of waste and improving efficiency. The results proved that the efficiency of the logistics could be improved using simulation modelling. 
Chen [7] proposes a model to optimise the production planning and scheduling, considering the logistics constraints. The author adopted the QPSO algorithm, which allowed resource maximization, greater efficiency and bringing benefit to the enterprise.

Suryani et al. [8] propose an urban transportation planning using the system dynamics simulation model. The objective was to optimise traffic management regarding congestion mitigation, improving urban mobility. By applying intelligent mobility modelling, the authors tested and evaluated strategies to mitigate traffic jams in the city of Surabaya, East Java, Indonesia.

Fragapane et al. [9] propose a study to simulate the logistics in hospitals. Through modelling of different scenarios, they can provide planners with support assistance, using the automated guided vehicle (AVG), which analyses the internal demand for goods, improving its delivery performance. The vehicle is operated by a radio-frequency communication system which allows the opening of doors and calling of elevators.

The objective of this paper is to propose a discrete event simulation model for a railyard and to compare the eco-efficiency of two classification strategies of wagons. The model considers the operations of train arrivals, wagon organization and classification, crossing control, wagons releasing to the port terminal, return to the railyard and sending back to their origin.

In addition to this introductory section, Section 2 presents the research methodology. Section 3 summarizes the theoretical concepts. Section 4 describes and analyses the Paranaguá "KM5" Railyard simulations. Section 5 presents the conclusions and directions for future works.

\section{RESEARCH METHODOLOGY}

This research is quantitative and descriptive, with a case study carried out in a "KM5" railyard placed in the Paranaguá City, Paraná, Brazil. The investigations were concentrated in the yard operations during the period June to November (2016), based on train scheduling of the company responsible for the yard in that period. For this, the design of the railyard, the worksheet with the schedule of trains arriving and leaving the yard, the description of the wagons, products and customers were obtained. Site survey and interviews were conducted with operation team technicians to understand how the yard is operated, how wagons are classified, in which lines they are parked, and the main problems they have faced. Using the results of the interviews and the site survey, it was possible to develop the simulation model of the railyard.

\section{THEORETICAL FOUNDATION}

Several scholars' research projects have been developed to study simulation models for specific rail transport systems, both passenger and cargo. Among these studies, it is possible to highlight the one carried out by Confessore et al. [10], the study regarding the railroad linking the cities of Verona and Brennero, Italy. The authors proposed the simulation and optimization to estimate the capacity of the pathway. The obtained results allowed a significant increase in the vehicle flow by reducing the train's interval, the environmental impact, energy consumption and improvement of the use of railway infrastructure, with the composition of freight and passenger trains sharing the same rails.

Crane et al. [11] developed a Monte Carlo simulation model for a freight railyard. According to the authors, these studies are important since freight wagons generally spend $2 / 3$ of their time parked in the yards or awaiting the classification of transported products. This 
brings inefficiency to the system, increased fuel, and environmental impact. Through the studies, the authors obtained positive results in reducing the total waiting time of the system.

The importance of simulation analysis in freight railways is due to the use of these systems for operational optimization. Railways in the USA accounted for $35.6 \%$ of cargo traffic [12]. Despite this, old-fashioned processes for increasing operational efficiency and processes rationalization are still adopted. Assad [12] describes several studies that have been developed in simulation and operational optimization, concluding their great advantage and how the development of new technologies could increase the scope of these analyses and the efficiency of the railways.

Munuzuri et al. [13] consider that freight train terminals require complex methods of planning management, systematically seeking to increase operational efficiency. However, with the increase of the terminals, this management becomes more and more complex, resulting in delays and problems of synchronism. The research proposes an algorithm-based simulation methodology to support this management. This process has been applied in the Port Terminal of Seville (Spain), bringing greater efficiency and manpower reduction.

Simulation models have advantages such as decision making without interfering with the operation of the existing system, testing of new equipment without the need for large investments, and acceleration or delay over time in phenomena that occur more slowly or fast. They also have disadvantages, such as the need for a great experience to operate the simulation model and the interpretation of the obtained data, the need for powerful computer resources and extreme care with the input and output data. Due to these needs, several systems have been developed to meet the increasingly complex modelling of rail transport, including GPSS ${ }^{\circledR}$, SIMAN V ${ }^{\circledR}$, SIMSCRIPT II.5 $^{\circledR}$, SLAM II $^{\circledR}$, ProModel / MedModel ${ }^{\circledR}$, AutoMod $^{\circledR}$, Taylor II ${ }^{\circledR}$, WITNESS $^{\circledR}$, SIMIO $^{\circledR}$ and ARENA ${ }^{\circledR}$.

$\mathrm{Xu}$ et al. [14] propose a mathematical formulation to analyse a better operational efficiency in the occupation of railway corridor lines. Xu analysed different types of models in linear programming and concluded that the solutions may not be very efficient in a real situation and that new studies could develop more adequate algorithms and that can reproduce more realistic conditions.

Wang and Goverde [15] propose an energy efficiency analysis for the distribution of schedules of a railway system through an optimization process, whose quality was verified through several indicators (KPIs).

According to Marinov et al. [16], traffic controllers are responsible for safety, efficiency, and trains movement on the track. The management of the system is conducted through "Operation Plans", which define the different occurrences that the operator must execute. These situations tend to be as broad as possible, depending on the good practices and frequencies that they may occur, including considering the risks of a decision not being made properly. However, the existence of a railway operation plan does not guarantee that there will be no accidents, from rolling stock failures, line conflicts and maintenance problems. Thus, the railway operation often requires the controllers to make decisions for conflict resolution. Such decisions may be classified as structured, unstructured, and semi-structured, as the result of the decision is certain and determined or uncertain and indeterminate, depending on its characteristics. The decision also involves the following phases: Intelligence (identification of what must be corrected), Project (identification of alternatives of conflict solutions), Choice (identification of the best alternative) and Implementation (execution of the solution). This demonstrates the importance of extensive analyses of the possible consequences of decision making and that the simulation processes allow a rapid and accurate evaluation of the various scenarios. Finally, the results of the scenarios can be expressed by indicators of technical, economic, safety or ecological efficiency, according to the adopted criteria by the decisionmaker. 
The concept of eco-efficiency was introduced by the World Bank in 1992 by [3] and has been widely adopted worldwide. Investors have sought ways to reduce the environmental impact of their business and at the same time increase development. The verification of ecoefficiency is done through indicators, which must be scientifically proven, relevant environmentally, accurate and usable for all types of business in the globe. According to the study, the eco-efficiency index is calculated through Eq. (1), which relates the product or value of the service to its influence on the environment.

$$
\text { Eco-efficiency }=\frac{\text { Product or Service Value }}{\text { Environmental influence }}
$$

In Eq. (1), the value of the product or service generally refers to the quantity of produced goods or services for customers, while the environmental influence refers to the consumption of energy, water, gas emissions or any other substances harmful to the environment. Different ventures or businesses will therefore have different ways of measuring the eco-efficiency indicator. The principles of described eco-efficiency by the World Bank used to evaluate the locomotives that travel on the Vitória-Minas Railroad (EFVM) [4]. An indicator used worldwide by railroads is the Gross Ton Kilometre (GTKM) which represents the sum of the total weight of the train multiplied by the distance. GTKM includes the weight of locomotives, wagons and all transported freight. Since GTKM has been widely used by railroads it was used as the service value $(\mathrm{V})$ for the method.

For environmental influence, seven indicators were adopted: The total energy consumption (E), total renewable energy consumption (RE), carbon dioxide emissions $\left(\mathrm{CO}_{2}\right)$, carbon monoxide emissions (CO), nitrogen oxides emissions (NOx), particulate matter emissions (PM) and cost efficiency (investment, maintenance and fuel) (CE). Different scenarios representing the exchange of fuel sources and technologies were developed, tested and analysed. The impacts were evaluated by seven ecoefficiency performance indicators and compared with the United States Environmental Protection Agency (EPA) standards. The results offered cost savings and reduction opportunities.

Regarding the simulation modelling system, the present study uses AnyLogic ${ }^{\circledR}$ software, still little known in Brazil, but widely used in the USA. This system has specific commands in railway operation that simplify its programming in addition to allowing a greater range of situations that can be simulated and evaluated. AnyLogic is one of the most widespread systems on the market in terms of groups on LinkedIn as well as published papers [17].

\section{DISCRETE EVENT-BASED SIMULATION MODEL FOR ECO-}

\section{EFFICIENCY EVALUATION - THE CASE OF PARANAGUÁ "KM5" RAILYARD}

\subsection{The "KM5" railyard}

The studied case refers to the freight railyard, also known as "KM5", belonging to the company Rumo Logistics, that receives wagons coming from the Paraná producing regions towards the port terminals of the Port of Paranaguá, which is in Paranaguá City, Paraná state, Brazil. Fig. 1 shows the regional location, detail of the port and the KM5.

\subsection{The input data}

For the development of the KM5 simulation model, a quantitative and qualitative analysis of the wagons, the daily schedules of the trains arriving at KM5, and the criterion of wagon positioning were carried out. 


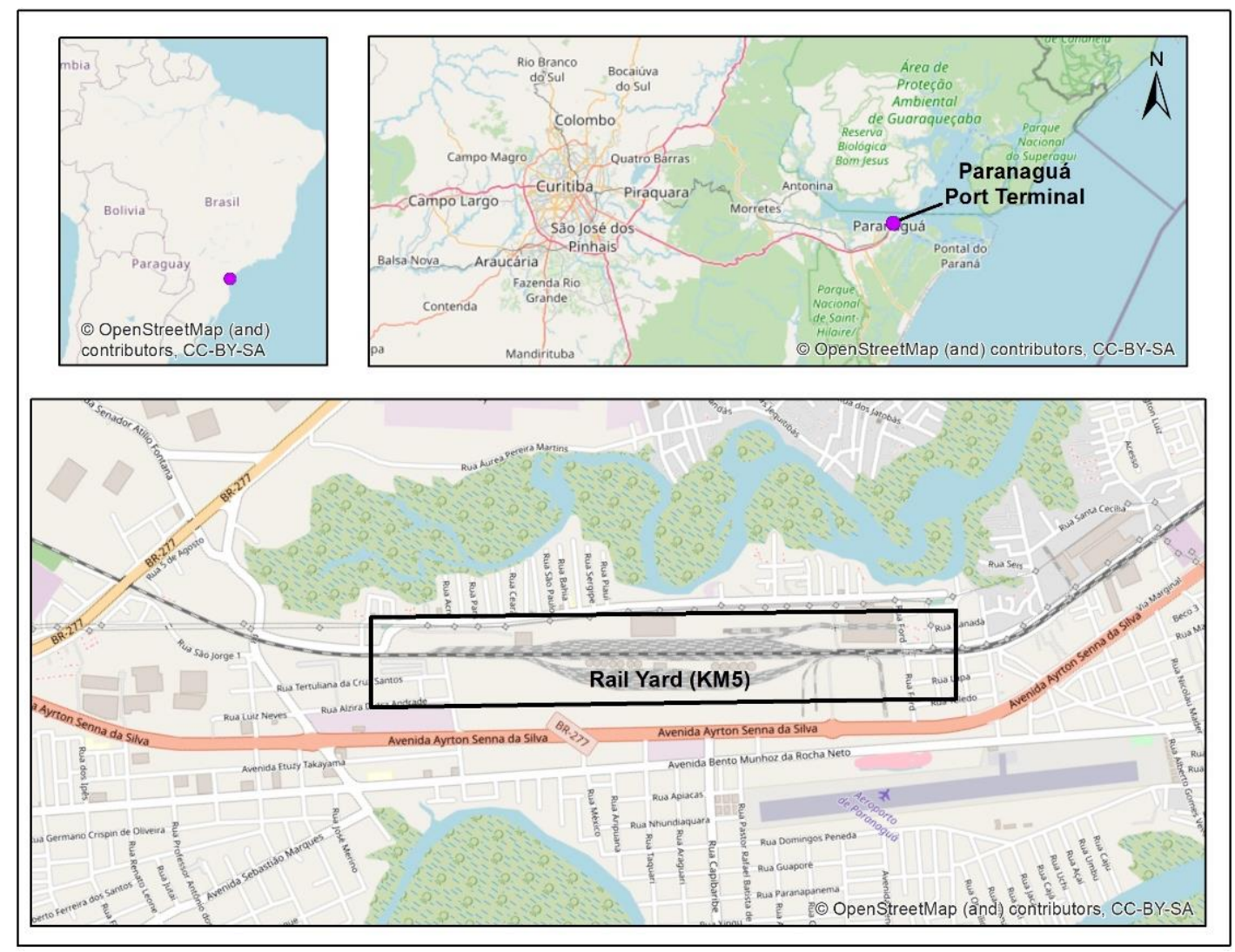

Figure 1: Port of Paranaguá and KM5 localization [18].

The quantitative analysis considers that the operation in KM5 consists of the arrival of the trains coming from the interior of Paraná through the mainline and that are sent to the reception lines. Once they are stationed, railway locomotives are switched off and wagons are classified and transferred to the parking lines using manoeuvring locomotives. After reaching several wagons of the same customer, between 50 and 70, the locomotive draws the wagons through the track to the cargo terminals in the port. Following, the wagons return to KM5, where they are surveyed and then taken back to their origin.

There is great variability in the daily quantities of arriving wagons, from 160 (June $9^{\text {th }}$ ) to 557 (June $15^{\text {th }}$ ). This variability makes it difficult to operate and manage resources in the KM5. Concerning the participation of each customer during this study period, it can be observed in Fig. 2 the great predominance of PASA and TCP wagons and low participation of Cargill wagons. This variation shows that while some lines are occupied and freed more often, others take more time for this process.

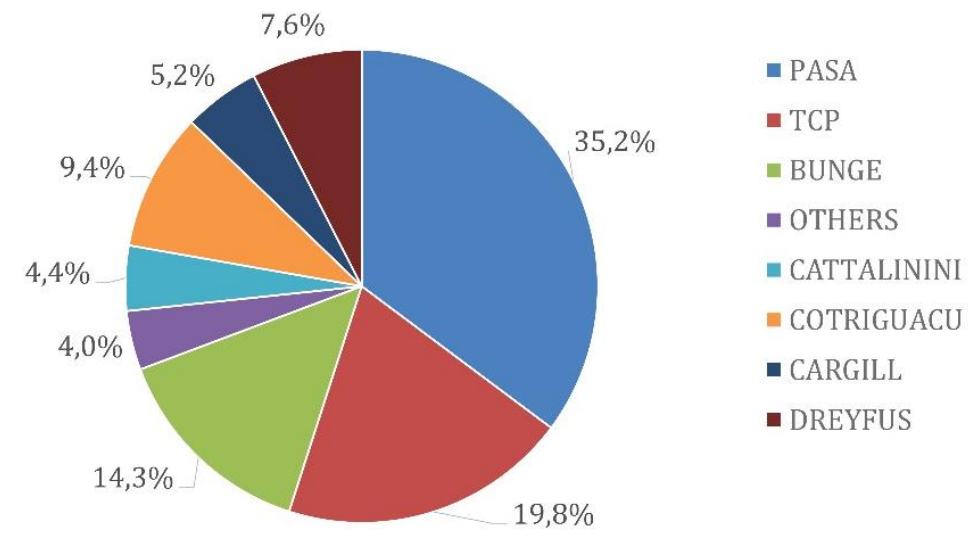

Figure 2: Total share of each Costumer (June / 2016). 
The qualitative wagon analysis establishes that the models of wagons used are gondola, hopper, platform and tank types, and their specifications are indicated in Table I [19].

Table I: Wagons types.

\begin{tabular}{|c|c|c|c|c|c|}
\hline Wagon code & Wagon model & Weight $(\mathrm{t})$ & $\begin{array}{c}\text { Load } \\
\text { capacity }(\mathrm{t})\end{array}$ & $\begin{array}{c}\text { Total } \\
\text { weight }(\mathrm{t})\end{array}$ & $\begin{array}{c}\text { Volume } \\
\left(\mathrm{m}^{3}\right)\end{array}$ \\
\hline HFD & Closed with hatch & 19.6 & 60.4 & 80.0 & 75.0 \\
\hline HFE & Hopper & 23.3 & 76.7 & 100.0 & 114.0 \\
\hline HPE & Hopper & 22.5 & 77.5 & 100.0 & 100.0 \\
\hline TCC & Tank & 18.0 & 38.7 & 64.5 & 42.0 \\
\hline TCD & Tank & 23.5 & 56.5 & 80.0 & 60.0 \\
\hline FBD & Gondola & 21.2 & 58.8 & 80.0 & 68.0 \\
\hline PCC & Platform & 10.5 & 53.5 & 64.0 & - \\
\hline PCD & Platform & 16.0 & 64.0 & 80.0 & - \\
\hline PEC & Platform & 12.0 & 36.0 & 48.0 & - \\
\hline PDD & Platform & 16.0 & 64.0 & 80.0 & - \\
\hline PEC & Platform & 12.0 & 36.0 & 48.0 & - \\
\hline PED & Platform & 16.0 & 64.0 & 80.0 & - \\
\hline PND & Platform & 12.4 & 51.6 & 64.0 & - \\
\hline PPC & Platform & 15.5 & 42.0 & 57.5 & - \\
\hline PQD & Platform & 15.0 & 27.0 & 42.0 & - \\
\hline
\end{tabular}

For the present study, it was assumed that all customers use HFE wagons, with a total weight of $100 \mathrm{t}$. The wagon moving operation is done through a worksheet to control schedules and destinations. Table II presents part of the worksheet containing information on the movement of the wagons in the KM5, which is related to the analysis period between June and November 2016.

Table II: Composition schedule.

\begin{tabular}{|c|c|c|c|c|c|c|}
\hline \multirow{2}{*}{$\begin{array}{c}\text { Train } \\
\text { code }\end{array}$} & \multirow{2}{*}{ Product } & Costumer & $\begin{array}{c}\text { Entrance to } \\
\text { KM5 }\end{array}$ & $\begin{array}{c}\text { KM5 to } \\
\text { terminal }\end{array}$ & $\begin{array}{c}\text { Terminal to } \\
\text { KM5 }\end{array}$ & $\begin{array}{c}\text { Exit from } \\
\text { KM5 }\end{array}$ \\
\cline { 4 - 7 } & & \multicolumn{4}{|c|}{ day / hour in September, 2016 } \\
\hline K78 & sugar & Pasa & $05 / 08: 00$ & $05 / 21: 21$ & $07 / 02: 14$ & $07 / 03: 05$ \\
\hline K78 & sugar & Pasa & $05 / 08: 00$ & $05 / 21: 21$ & $07 / 02: 14$ & $07 / 03: 05$ \\
\hline K78 & sugar & Pasa & $05 / 08: 00$ & $05 / 21: 21$ & $07 / 02: 14$ & $07 / 03: 05$ \\
\hline K78 & sugar & Pasa & $05 / 08: 00$ & $05 / 21: 21$ & $07 / 02: 14$ & $07 / 03: 05$ \\
\hline K78 & soybean & Cotriguacu & $05 / 08: 00$ & $05 / 08: 40$ & $10 / 18: 21$ & $10 / 19: 20$ \\
\hline K78 & soybean & Cotriguacu & $05 / 08: 00$ & $05 / 08: 40$ & $10 / 04: 08$ & $10 / 05: 40$ \\
\hline K78 & soybean & Cotriguacu & $05 / 08: 00$ & $05 / 08: 40$ & $10 / 04: 08$ & $10 / 05: 40$ \\
\hline K78 & soybean & Cotriguacu & $05 / 08: 00$ & $05 / 08: 40$ & $10 / 18: 21$ & $10 / 19: 20$ \\
\hline
\end{tabular}

As shown in Table II, each line represents the relative data of a wagon, indicating the code of the incoming train (train code), input merchandise (product), costumer, day and time of movements when the train arrives at the KM5 (entrance to KM5) when it leaves the KM5 and arrives at the terminal (KM5 to the terminal) when it leaves the terminal and goes to KM5 (terminal to KM5) and when it exits KM5 back to this origin (exit from KM5). Each train arriving at KM5 (for example K78 in Table II) is composed of a set consisting of Pasa and Cotriguaçú wagons. The first step to use the obtained information from the rail operator Rumo was to transform the original data format (Table II) into a format that could be interpreted by the simulation program. In this phase an input data analysis was performed, aiming to eliminate inconsistent data such as wagons without customer or product indication, very short time interval between sequential trains and a very small number of wagons per train. Table III shows the adopted solutions. 
During the interview with the operators, it was reported that one part of the lines had one defined operator, while another part was of common use. Table IV shows how lines (railways) are organized in yard KM5 according to their occupation or use.

Table III: Problems with input data and adopted solutions.

\begin{tabular}{|l|l|}
\hline \multicolumn{1}{|c|}{ Problem } & \multicolumn{1}{c|}{ Solution } \\
\hline Wagons without customer or product indication & $\begin{array}{l}\text { Removal of wagons or adoption of wagon products of the } \\
\text { same composition }\end{array}$ \\
\hline The short time interval between sequential trains & The consideration that it is the same train \\
\hline A very small number of rail wagons per train & Elimination \\
\hline
\end{tabular}

Table IV: Utilization of KM5's lines.

\begin{tabular}{|c|c|l|}
\hline Line & Export/ Import & Cargo \\
\hline L1, L3, L3A, L7, L9, & Uninformed & Uninformed \\
\hline L11, L13, L15, L17 & Uninformed & Train reception \\
\hline L2 & Export & Train reception \\
\hline L4, L6 & Uninformed & Train reception \\
\hline L8 & Import & Grains, sugar Pasa \\
\hline L10 & Import & Grains, sugar Bunge \\
\hline L12 & Import & Grains, bran Cotriguaçu \\
\hline L14 & Import & Grains, bran Cargill \\
\hline L16 & Import & Grains, bran Dreyfus \\
\hline L18 & Import & Cattalini + vegetable oil + empty cargo tanks \\
\hline L19 & Export & Fertilizers \\
\hline L21, L23 & Export & Empty wagons \\
\hline L22 & Import & Platform wagons with a container for TCP \\
\hline L24 & Import & Terminal circulation Line \\
\hline L25 & Export & Containers and tank wagons \\
\hline L27 & Export & Empty wagons \\
\hline
\end{tabular}

As shown in Table IV, while odd lines are used to exit the trains to the origin, the even lines receive the destined wagons for the terminals, with certain lines having defined customers, while others are used for other purposes.

Fig. 3 shows the schematic of KM5 and Fig. 4 shows the detail of the lines with the nomenclature of each one of them, the even lines being for the wagons that are destined for the port and the odd ones for the wagons coming from the port.

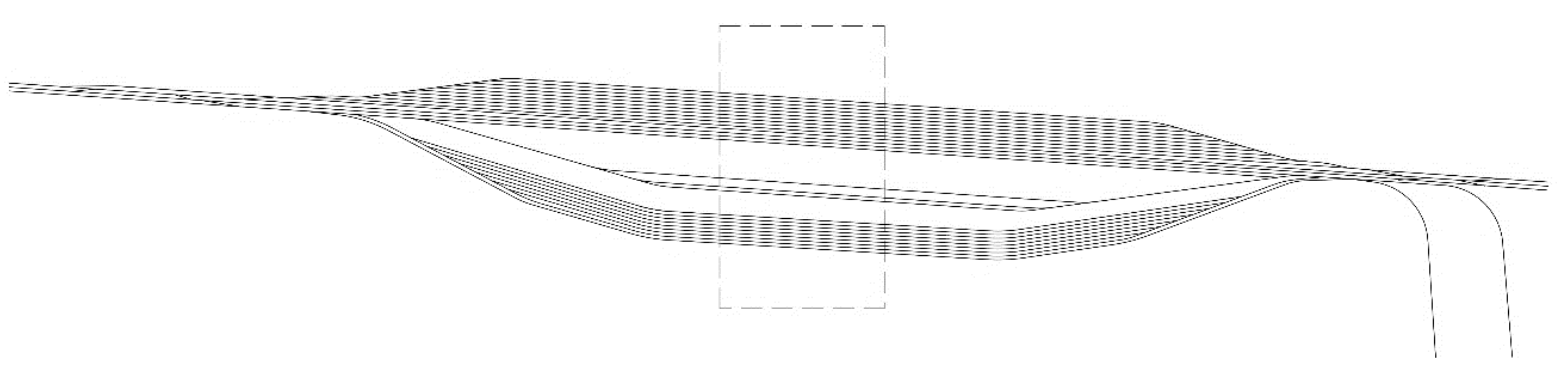

Figure 3: Modelling of the geometry.

From the left side of the KM5, the trains arrive from the producing regions of Paraná and on the right, they follow towards the port terminals. In the North and the Southside are parked, respectively, the wagons coming from the production regions and the port terminals. The model simulates the North lines, which are named according to Table IV and highlighted by the dashed area, as enlarged in Fig. 4.

As indicated in Table IV, there are lines for specific customers and lines without defined destination or customers without own line (Fertipar, Fospar, Interalli, Klabin, Santa Terezinha, 
Yara-KM5, Multitrans, Rocha Top-Fertilizantes, Seara, export corridor and Rumo). In this case, a grouping of all with the fictitious name "Other" was adopted, which will be parked on a common line.

PARKING LINES FOR WAGONS COMMING FROM THE PORT

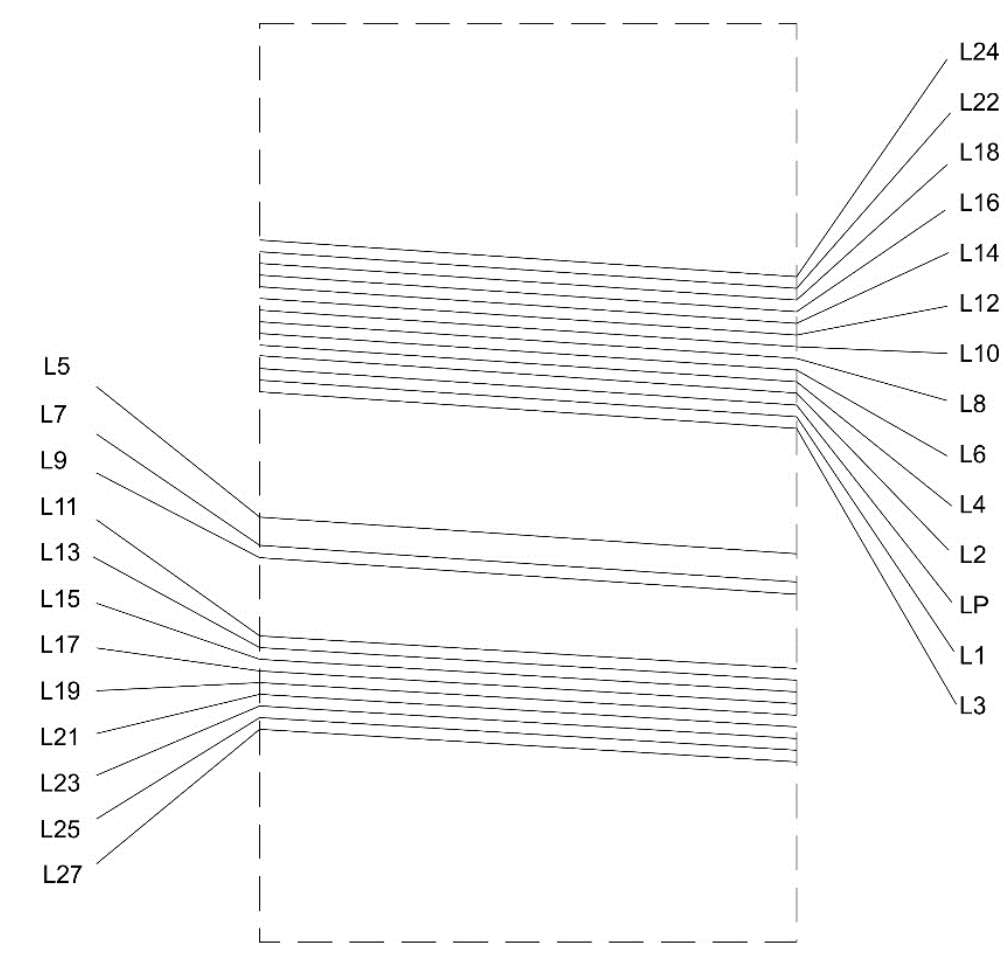

Figure 4: Detail of the used lines by the companies.

\subsection{The discrete event-based model}

After inserting the geometric data of the tracks in the software AnyLogic, the rules of trains movement and entry point in the yard are defined. to the logic is defined for the separation of the wagons from the traction locomotive, the movement of wagon blocks, their parking and releasing to the port terminals. The next step is to study the restrictions on the movement of trains and wagons in terms of maximum quantity per line, passage priorities at crossing points and paths that the locomotives should travel during manoeuvres. Finally, the scenarios of wagon classification are simulated to identify possible restrictions of the system and proposing solutions to eliminate them.

The AnyLogic simulation model based on discrete events considers that each event occurs at a specific time, in this case, the arrival time of the trains to KM5. From there, it moves locomotives and wagons following the defined operational criteria, through coupling and decoupling movements of locomotives, as well as the defined decision-making by the system.

\subsection{The classification yard strategies}

After the arrival of the trains to the KM5 and liberation of the traction locomotives, the work of the manoeuvre locomotives begins, aiming to classify the wagons in their respective lines. This classification can be performed by two strategies. The first one (option 1), named in-block classification, consists of the traction of all wagons blocks at the same time, that is, every composition is drawn whole, with each group of the same customer being disconnected sequentially in their respective line. The second strategy (option 2), called separate sorting of wagons, consists of the manoeuvring locomotive separating groups of wagons into blocks of the same customer, taking each block separately to its parking line, returning to fetch the next block until all blocks are parked. Each option has advantages and disadvantages. Blocked 
classification means that the manoeuvre locomotive must travel less time than the separate classification but pulling more wagons at the same time.

\subsection{Model rules}

For the elaboration of the model by AnyLogic, a series of modelling rules were considered: All wagons have $100 \mathrm{t}$ of total weight, the traffic speed is equal to $5 \mathrm{~km} / \mathrm{h}$. Additionally, the model considers that when some parking line reaches 50 wagons, they shall be pulled by the locomotive manoeuvre to the terminal, emptying this line. Another rule refers to the maximum number of wagons that would fit within the limits of each parking line. The purpose of this limit is to verify the hypothesis of the total sum of the wagons already parked on the line, still, less than 50, with wagons from a new group exceeds the physical limits of this line, parking several wagons over the mainline. These excesses of wagons may prevent other wagons from heading to their respective lines, causing the stoppage of the train yard. Table V shows the physical limit of each line and the variable adopted in the modelling.

Table V: KM5 lines utilization.

\begin{tabular}{|c|c|}
\hline Line & Physical capacity \\
\hline L8 & 78 \\
\hline L10 & 75 \\
\hline L12 & 71 \\
\hline L14 & 68 \\
\hline L16 & 65 \\
\hline L18 & 62 \\
\hline L22 & 59 \\
\hline L24 & 58 \\
\hline
\end{tabular}

When a group of new wagons from a customer arrives at KM5, the program checks if the number of wagons already parked on their line added to this new group exceeds the physical capacity of the line. If this occurs, the manoeuvring locomotive receives an order to pre-empty the line, freeing up space for the new wagons to be parked.

The third rule solves a specific situation of the blocked classification of the wagons into the parking lot. If, for example, a train arrives at KM5 with a group of wagons such that the first group of wagons to be parked contains more than the capacity of its line, this first group may leave wagons invading the line which serves as another parking area, causing a conflict. The solution was to adopt, in the programming logic, prior verification of this situation and, when this happens, the model temporarily changes the positioning option of the wagons, ungrouping them and performing the separate classification. The next train that arrives will resume the blocked classification.

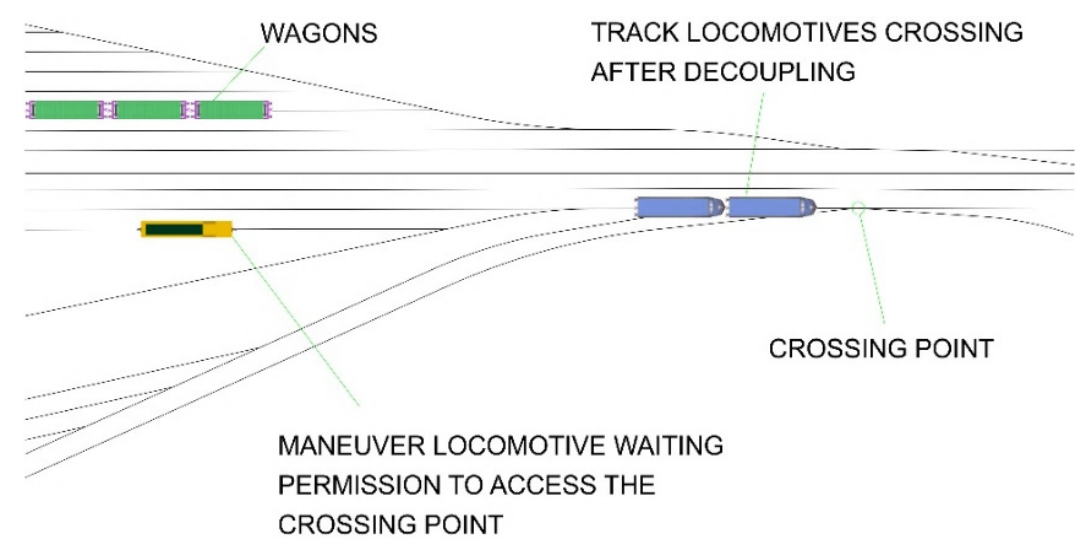

Figure 5: Crossing point on the tracks. 
Regarding the safety of crossings, the program tried to perform a signalling analysis at the points of conflict. Fig. 5 shows the crossing of lines between the manoeuvring locomotive and the traction locomotives. The simulation model predicts that the crossover point can only be accessed if it is free. It can be observed that the two traction locomotives can pass at the intersection. The locomotive must wait for its clearance.

\subsection{Eco-efficiency evaluation}

To evaluate the eco-efficiency of the proposed classification strategies, two simulations were carried out for the month of June 2016. The maneuverer locomotive movement data was obtained, such as the total displacement time of the maneuverer locomotive in hours, the distance travelled $(\mathrm{km})$ and GTKM (ton $\times \mathrm{km}$ ) as shown in Table VI. These values served as parameters for the calculation of eco-efficiency indexes.

Table VI: Scenarios summary.

\begin{tabular}{|c|c|r|r|}
\hline Scenario & Unity & Option 1 & Option 2 \\
\hline Time & $\mathrm{h}$ & 219.84 & 252.71 \\
\hline Distance & $\mathrm{km}$ & $1,099.18$ & $1,263.55$ \\
\hline GTKM & ton $\times \mathrm{km}$ & $3,743,310.56$ & $3,068,969.51$ \\
\hline
\end{tabular}

The calculated efficiency ratios are total energy consumption (E), Carbon dioxide emissions $\left(\mathrm{CO}_{2}\right)$, Carbon monoxide emissions (CO), Nitrogen oxides emissions ( $\left.\mathrm{NO}_{\mathrm{X}}\right)$, Particulate matter emissions (PM) and Total cost (investment, maintenance and fuel) (CE).

The following technical parameters were used [18]: Fuel consumption $(F E)=292.91 \mathrm{l} / \mathrm{h}$; Calorie content of fuel $(C C)=37.711 \mathrm{~kJ} / 1$; Cost of fuel $(F U)=\mathrm{US} \$ 1.09 / 1 ; \mathrm{CO}_{2}$ fuel emission factor $(E C)=2.71 \mathrm{~kg} / 1$; $\mathrm{CO}$ fuel emission factor $(E O)=4.5 \mathrm{~g} / 1$; $\mathrm{NO}_{\mathrm{X}}$ fuel emission factor $(E N)=44.3 \mathrm{~g} / \mathrm{l}$; Particulate matter fuel emission factor $(E P)=1.62 \mathrm{~g} / 1$.

The total renewable energy consumption (eiRE), the MC (the maintenance cost) and IC (investment cost) were not included in this analysis. Table VII shows the results of simulated classification strategies.

Table VII: Summary of classification strategies.

\begin{tabular}{|c|c|c|c|c|}
\hline & Scenario & Unit & Option 1 & Option 2 \\
\hline \multirow{6}{*}{ Calculated efficiency } & $\mathrm{eiE}$ & $\mathrm{kJ}$ & $2,428,296.53$ & $2,791,416.72$ \\
\hline & $\mathrm{eiCO}_{2}$ & $\mathrm{Kg}$ & $173,859.10$ & \begin{tabular}{|l|}
$199,857.47$ \\
\end{tabular} \\
\hline & eiCO & $\mathrm{kg}$ & 37.31 & 42.88 \\
\hline & $\mathrm{eiNO}_{\mathrm{X}}$ & $\mathrm{kg}$ & $2,852.58$ & $3,279.14$ \\
\hline & eiPM & $\mathrm{kg}$ & 104.32 & 119.91 \\
\hline & eiCE & US\$ & $70,187.56$ & $80,683.20$ \\
\hline \multirow{6}{*}{ Eco-efficiency index } & $\mathrm{E}$ & ton $\times \mathrm{km} / \mathrm{kJ}$ & 1.54 & 1.10 \\
\hline & $\mathrm{RE}$ & ton $\times \mathrm{km} / \mathrm{kg}$ & 21.53 & 15.36 \\
\hline & $\mathrm{CO}_{2}$ & ton $\times \mathrm{km} / \mathrm{kg}$ & $100,340.40$ & $71,563.17$ \\
\hline & $\mathrm{NO}_{\mathrm{X}}$ & ton $\times \mathrm{km} / \mathrm{kg}$ & $1,312.26$ & 935.91 \\
\hline & PM & ton $\times \mathrm{km} / \mathrm{kg}$ & $35,884.52$ & $25,592.98$ \\
\hline & $\mathrm{CE}$ & ton $\times \mathrm{km} / \mathrm{US} \$$ & 53.33 & 38.04 \\
\hline
\end{tabular}

Based on the obtained results, it can be observed that option 1 is more advantageous than option 2. Option 1 required $13 \%$ less time and generates an accumulated transportation moment $22 \%$ higher. This translates into less cost of the use of the locomotives and higher freight handling. Regarding eco-efficiency indexes, option 1 has $40 \%$ higher indexes than option 2 . This shows that less environmental impact is caused by moving all the wagon blocks at the same time than by cutting the composition into separate blocks. The simulations carried out in this paper were made available for online execution through the electronic addresses. 
Option 1 simulation: https://bit.ly/3gbJ6tF

Option 2 simulation: https://bit.ly/3gdoSQ1

\section{CONCLUSIONS}

This paper demonstrates that several aspects need to be considered to evaluate the environmental impact of on railway operation. Not only the fuel consumption itself but how efficiently it is being consumed. This new methodology of analysis can help to see how different strategies of operation can influence the results of the railyard management.

The interviews with rail operators demonstrated that different situations require different decisions and often uncommon ones at that. In this context, extensive knowledge of the rules of wagon movement is fundamental so that the model can represent the operation in a train yard more accurately. The installation of railyard surveillance cameras would enable the observation of daily events and movement, also helping in the informed definition of programming logic.

AnyLogic is very robust and efficient software for modelling and simulation. Its specific functions for railway evaluation facilitate the development of ever more complex models, allowing a wide range of situations to be reproduced.

The analysis of the eco-efficiency indexes can be expanded considering different models of wagons, with different capacities, dimensions and weights, different classes of locomotives and the types of cargo that are transported. Different solutions for engines and their fuel can also be evaluated using this process.

The application of a simulation model for the analysis of eco-efficiency is quite efficient since it allows the rapid surveying of cargo movement. Moreover, this method allows other studies such as the exit operation of the wagons back to their origin and their operation in the region of the port terminals. This knowledge allows for the development of manuals and wider operation standards, including situations and problems not precisely evaluated with such precision by traditional methods. Besides, different models of locomotives and wagons can be compared to identify the ones that bring more efficiency to the system.

\section{ACKNOWLEDGEMENTS}

The present study was carried out with the support of the Coordination of Improvement of Higher Education Personnel - Brazil (CAPES, Coordenação de Aperfeiçoamento de Pessoal de Nível Superior - Brasil) - Financing Code 001. To the professors Renata Albergaria and Paulo Afonso Lopes for the orientations, revisions and collaboration for this paper.

\section{REFERENCES}

[1] AnyLogic. Simulation software, from http://www.anylogic.com/, accessed on 03-05-2018

[2] Chwif, L.; Medina, A. C. (2006). Modelagem e Simulações de Eventos Discretos - Teoria \& Aplicações, Palas Athena, São Paulo

[3] Verfaillie, H. A.; Bidwell, R. (2000). Measuring Eco-Efficiency. A Guide to Reporting Company Performance, World Business Council for Sustainable Development, Geneva

[4] Carvalhaes, B. B.; Rosa, R. D. A.; D'Agosto, M. D. A.; Ribeiro, G. M. (2017). A method to measure the eco-efficiency of diesel locomotive, Transportation Research Part D: Transport and Environment, Vol. 51, 29-42, doi:10.1016/j.trd.2016.11.031

[5] Fan, W. G.; Hou, G. Y.; Wang, W. X.; Zhang, X. L.; Wang, J. D. (2019). Design and dynamic analysis of a new rail grinding device using closed abrasive belt, International Journal of Simulation Modelling, Vol. 18, No. 3, 531-542, doi:10.2507/IJSIMM18(3)CO14

[6] Wang, Y. R.; Chen, A. N. (2016). Production logistics simulation and optimization of industrial enterprise based on Flexsim, International Journal of Simulation Modelling, Vol. 15, No. 4, 732741, doi:10.2507/IJSIMM15(4)CO18 
[7] Chen, Y. X. (2016). Integrated optimization model for production planning and scheduling with logistics constraints, International Journal of Simulation Modelling, Vol. 15, No. 4, 711-720, doi:10.2507/IJSIMM15(4)CO16

[8] Suryani, E.; Hendrawan, R. A.; Adipraja, P. F. E.; Indraswari, R. (2020). System dynamics simulation model for urban transportation planning: a case study, International Journal of Simulation Modelling, Vol. 19, No. 1, 5-16, doi:10.2507/IJSIMM19-1-493

[9] Fragapane, G. I.; Zhang, C.; Sgarbossa, F.; Strandhagen, J. O. (2019). An agent-based simulation approach to model hospital logistics, International Journal of Simulation Modelling, Vol. 18, No. 4, 654-665, doi:10.2507/IJSIMM18(4)497

[10] Confessore, G.; Liotta, G.; Cicini, P.; Rondinome, F.; De Luca, P. (2009). A simulation-based approach for estimating the commercial capacity of railways, Proceedings of the 2009 Winter Simulation Conference, 2542-2552, doi:10.1109/WSC.2009.5429664

[11] Crane, R. R.; Brown, F. B.; Blanchard, R. O. (1955). An analysis of a railroad classification yard, Journal of the Operation Research Society of America, Vol. 3, No. 3, 262-271, doi:10.1287/opre.3.3.262

[12] Assad, A. A. (1980). Models for rail transportation, Transportation Research Part A: General, Vol. 14, No. 3, 205-220, doi:10.1016/0191-2607(80)90017-5

[13] Munuzuri, J.; Domingueza, I.; Berrocal, M. A.; Escudero, A. (2016). An allocation-scheduling heuristic to manage train traffic in an intermodal terminal, Computers in Industry, Vol. 82, 196204, doi:10.1016/j.compind.2016.07.006

[14] Xu, Y.; Jia, B.; Ghiasi, A.; Li, X. (2017). Train routing and timetabling problem for heterogeneous train traffic with switchable scheduling rules, Transportation Research Part C: Emerging Technologies, Vol. 84, 196-218, doi:10.1016/j.trc.2017.08.010

[15] Wang, P.; Goverde, R. M. P. (2019). Multi-train trajectory optimization for energy-efficient timetabling, European Journal of Operational Research, Vol. 272, No. 2, 621-635, doi:10.1016/j.ejor.2018.06.034

[16] Marinov, M.; Sahin, I.; Ricci, S.; Vasic-Franklin, G. (2013). Railway operations, time-tabling and control, Research in Transportation Economics, Vol. 41, No. 1, 59-75, doi:10.1016/ j.retrec.2012.10.003

[17] GENOA. Anylogic para Simulação de Porto, Rodovias e Ferrovias, from http://www.genoads.com.br, accessed on 19-03-2019

[18] Prefeitura de Paranaguá. Paranagua Port, from http://www.paranagua.pr.gov.br, accessed on 1903-2019

[19] Centro-Oeste. Brazilian Rail History, from http://vfco.brazilia.jor.br, accessed on 28-02-2019 